\title{
Urinary Homogentisic Acid in Alkaptonuric and Healthy Children
}

\author{
Anna V. Oláh ${ }^{1 *}$, István Ilyés ${ }^{2}$, Attila Szőke ${ }^{3}$, István \\ Csízy², Judit Tóth ${ }^{2}$ and József Varga ${ }^{4}$ \\ 1 Department of Clinical Biochemistry and Molecular \\ Pathology, \\ 2 Department of Pediatrics, \\ University of Debrecen, Medical and Health Science Center, \\ Debrecen, Hungary \\ 3 Pediatric Department, University of Pécs, Pécs, Hungary \\ ${ }^{4}$ Department of Nuclear Medicine, University of Debrecen, \\ Medical and Health Science Center, Debrecen, Hungary
}

To detect and follow-up the metabolic status of patients with alkaptonuria (AKU), urinary homogentisic acid (HGA) was measured by gas chromatography. These results were close to values we obtained by colorimetric method (linearity: up to $700 \mathrm{mg} / \mathrm{l}$, detection limit: $1 \mathrm{mg} / \mathrm{l}$, within-run imprecision (CV): $1.2 \%$ at $100 \mathrm{mg} / \mathrm{l} \mathrm{HGA}, 4.9 \%$ at $10 \mathrm{mg} / \mathrm{l}$, between-run CV: $6.8 \%$ at $100 \mathrm{mg} / \mathrm{l}$ ). To determine urinary reference ranges of HGA, 84 healthy children (age: 2 months-18 years) were divided into five age groups. HGA and creatinine were measured in their morning urine. Statistical analysis proved that urinary $\mathrm{HGA} /$ creatinine ratio is age-dependent. The ratio is relatively high between 1 and 6 years of age, with large scatter (upper limit of reference ranges given as mean + 2SD: $5.5-7.2 \mathrm{mg} / \mathrm{mmol}=0.03-0.04 \mathrm{mmol} / \mathrm{mmol}$ creatinine), and it decreases with age. Approximately at the age of 7 years, HGA/creatinine ratio becomes constant, and later it is similar to the adult value (upper limit: $2.8 \mathrm{mg} /$ $\mathrm{mmol}=0.017 \mathrm{mmol} / \mathrm{mmol}$ creatinine). We monitored a patient during her $1-5$ th year of life, and her urinary HGA was 80-200 times higher than the upper limit of the agematched reference ranges. The measurement of HGA supports the decision for starting restricted protein diet and is useful for the evaluation of the effectiveness of therapy. Clin Chem Lab Med 2003; 41(3):356-359

Key words: Alkaptonuria; Homogentisic acid; Reference range.

Abbreviations: AKU, alkaptonuria; ANOVA, analysis of variance; $\mathrm{CV}$, coefficient of variation; GC-MS, gas chromatography-mass spectrometry; HGA, homogentisic acid.

\section{Introduction}

Alkaptonuria (AKU) is one of the first described metabolic disorders, with well-known symptoms $(1,2)$. It was interpreted as a Mendelian trait by Garrod and Bateson. Prevalence of AKU is relatively low in Europe

$\bar{*}$ E-mail of the corresponding author: olaha@jaguar.dote.hu
(1:100000-250000) but increased AKU prevalence (1:19000) has been described recently in a geographical region of Slovakia (3).

AKU results from the deficiency of homogentisic acid dioxygenase, an enzyme required for the catabolism of phenylalanine and tyrosine, and may be characterized by increased urinary excretion of homogentisic acid (HGA). The accumulation, oxidation, and polymerization of HGA cause pigmentation of cartilage and connective tissues, and later lead to the development of inflammatory arthropathy, and sometimes cardiovascular disease (4-6). The effects of redox property of HGA with regard to human hemoglobin have been studied recently $(7,8)$ and the results identified a new aspect of AKU. These long-term effects emphasize the importance of monitoring HGA levels in these patients. For the treatment of AKU, dietary protein restriction and high-dose vitamin $C$ are suggested to decrease HGA excretion $(9,10)$. As the long-term effect of diet is uncertain, and dietary compliance decreases with age, checking the individual urinary levels of HGA helps to make decisions on starting restricted protein diet and its duration $(6,10,11)$.

After detection of HGA in a 6 months' old AKU patient in our department, it was necessary to find an available, reliable method for the follow-up of urinary HGA, and to compare it to the appropriate reference range. Recently developed methods for the determination of HGA, such as mass spectrometry, nuclear magnetic resonance, and capillary electrophoresis, are not cost-effective or available as screening tests $(12,13)$. Ascending chromatography is not a quantitative test and the colorimetric method described earlier is rather inconvenient because of the extraction of HGA and oxidation of p-hydroxyphenyl-pyruvic acid (14).

The aims of this study were to develop and validate a reliable colorimetric method, to establish the reference range for the urinary HGA concentration, and to follow urinary HGA levels in our AKU patient considering the reference range.

\section{Materials and Methods}

In order to determine the reference range, we studied 84 morning urinary samples from healthy children (age: 2 months-18 years), who were free of chronic or infectious diseases. The samples were centrifuged and tested within 4 hours. Five age groups were established: 1 st: $0-1$ year $(n=$ 11), 2nd: $2-3$ years $(n=14), 3 r d: 4-6$ years $(n=15)$, 4th: $7-10$ years $(n=15)$, and 5 th: $11-18$ years $(n=29)$.

\section{Colorimetric assay}

HGA was determined by a kinetic method using the same Nylander-reagent that we use for the detection of reducing compounds in urine. The reagent contained $2 \mathrm{~g}$ bismuth-nitrate, 
$4 \mathrm{~g}$ potassium sodium-tartarate, and $10 \mathrm{~g}$ sodium-hydroxide in $100 \mathrm{ml}$ distilled water. Two hundred $\mu \mathrm{l}$ of this reagent was added to the mixture of $200 \mu \mathrm{l}$ urine and $2 \mathrm{ml}$ distilled water. The reaction mixture was kept at room temperature $\left(25^{\circ} \mathrm{C}\right)$ for $5 \mathrm{~min}$, and then the absorbance of the forming brown compound was measured by spectrophotometry (Specord M40, Jena, Germany) at $575 \mathrm{~nm}$, in $1 \mathrm{~cm}$ cuvette, against reagent blank.

The AKU patient's urine was 10 times prediluted with distilled water before analysis. Absorbance was read exactly after $5 \mathrm{~min}$ to avoid nonspecific reduction of metal ions with other compounds, (for instance, gentisic acid, hydroquinone, and catechol react with silver ions only after $60 \mathrm{~min}$ (15)). To decrease interference with vitamin $\mathrm{C}$, we interrupted vitamin $C$ therapy during urine collection.

One hundred $\mathrm{mg} / \mathrm{l}$ or $50 \mathrm{mg} / \mathrm{l} \mathrm{HGA}$ calibrators were made of HGA (free acid form of 2,5-dihydroxyphenylacetic acid, Sigma, St. Louis, USA) and distilled water. Linearity and detection limit were assessed by serial dilution of the stock $1000 \mathrm{mg} / \mathrm{l} \mathrm{HGA}$ solution, using duplicate samples.

To avoid imprecision associated with 24 hours urine collection and the decomposition of HGA, first urine samples were taken during the morning hours. In order to compensate for the daily fluctuation in excretion, urinary HGA levels were expressed as the ratio of $\mathrm{HGA}$ to creatinine concentration ( $\mathrm{HGA} / \mathrm{creatinine} ; \mathrm{mg} / \mathrm{mmol}$ or $\mathrm{mmol} / \mathrm{mmol}$ ). Urinary creatinine was determined by Jaffe's method.

\section{Gas chromatographic analysis of HGA}

The sample maintenance, extraction steps, derivatization, and gas chromatographic quantification was the routine urine organic acid analysis on the base of the classic Tanaka method (16). The urine sample premeasured for creatinine was internal standardized with pentadecanoic acid. After acidification, the aqueous phase was extracted to ether-ethylacetate organic solvent mixture. This phase was dried under nitrogen stream, dissolved with pyridin-trimethylsilyil reaction mixture, and heated at $60^{\circ} \mathrm{C}$ for $30 \mathrm{~min}$. One microliter aliquot was injected to OV-1 packed column. The instrument was Chrom-5 GC with FID-detector (Lab. Pristroje, Prague, Czech Republic), interfaced with Shimadzu integrator.

\section{Statistical analysis}

Age dependence was tested using analysis of variance (ANOVA). To find out age groups where HGA and HGA/creati- nine levels were significantly different from those of the oldest group (age 11-18 years), either Student's t test, or Welch's $d$ test was applied, depending on the results of $F$ test for the comparison of group variances.

\section{Results}

As it was not clear whether urinary HGA excretion is age-dependent, we determined reference ranges in children aged from 2 months to 18 years. As HGA (mg/l) reference ranges do not change significantly above 1 year of age, the same reference ranges can be used either in children and adults. Although reference ranges seem not to be very important in the case of AKU patients - their HGA value is several 100-fold higher - validation of colorimetric method was necessary. The colorimetric method is suitable for the determination of urinary HGA excretion in a screening test. The detection limit is $1 \mathrm{mg} / \mathrm{l}$ in the assay described above. The assay proved to be linear between 1-700 $\mathrm{mg} / \mathrm{l}$. The within-run imprecision (coefficient of variation, $\mathrm{CV}$ ) of the assay was $1.2 \%$ at $100 \mathrm{mg} / \mathrm{l} \mathrm{HGA}$, and $4.9 \%$ at $10 \mathrm{mg} / \mathrm{l}(\mathrm{n}=10)$. Between-run CV was $6.8 \%$ at $100 \mathrm{mg} / \mathrm{l}(\mathrm{n}=6)$.

It can be concluded from the statistical analysis of 84 urinary samples, that urinary HGA concentration is age-dependent (Table 1), being significantly lower in the first year of life than later.

Although the HGA concentration increases with age, urinary creatinine increases more rapidly. For this reason the $\mathrm{HGA}$ /creatinine quotient is strongly age-dependent (ANOVA: $p<0.001$ ), being significantly higher below the age of 6 years than after that age $(p<0.05$, Welch's d test; see Table 1). The means of HGA/creatinine at age 7-10 and 11-18 years do not show significant difference ( $p>0.1$, Student's t test).

Generally, we can conclude that the HGA/creatinine quotient is relatively high during the first 6 years of life, with a large scatter (upper limit of the reference range given as mean + 2 SD: $5.5-7.2 \mathrm{mg} / \mathrm{mmol}$ ), and shows a tendency towards decrease with age. At the age of approximately 7 years, this value becomes constant and similar to the HGA excretion in adults (upper limit of the

Table 1 Reference ranges for urinary homogentisic acid (HGA) concentration (mg/l) and homogentisic acid/creatinine ( $\mathrm{HGA} / \mathrm{creatinine})$ quotient $(\mathrm{mg} / \mathrm{mmol})$ in various age groups in children.

\begin{tabular}{|c|c|c|c|c|c|c|}
\hline Age (years) & & $0-1$ & $2-3$ & $4-6$ & $7-10$ & $11-18$ \\
\hline $\mathrm{n}$ & & 11 & 14 & 15 & 15 & 29 \\
\hline \multirow{5}{*}{$\begin{array}{l}\text { HGA/creatinine } \\
\text { (mg/mmol) }\end{array}$} & Mean & 2.41 & 2.82 & 2.79 & 1.29 & 1.23 \\
\hline & SD & 1.56 & 2.23 & 2.06 & 0.56 & 0.79 \\
\hline & \multicolumn{4}{|l|}{$\mathrm{t}(v s .11-18$ years) } & 0.803 & \\
\hline & $\mathrm{d}(v s .11-18$ years) & 0.034 & 0.021 & 0.012 & & \\
\hline & $\mathrm{F}$ & 0.004 & 0.000 & 0.000 & 0.170 & \\
\hline \multirow{4}{*}{$\begin{array}{l}\text { HGA } \\
(\mathrm{mg} / \mathrm{l})\end{array}$} & Mean & 5.33 & 9.29 & 11.53 & 11.25 & 12.26 \\
\hline & SD & 4.69 & 6.43 & 6.24 & 7.37 & 4.98 \\
\hline & $\mathrm{t}(v s .11-18$ years) & 0.008 & 0.254 & 0.869 & 0.724 & \\
\hline & $\mathrm{F}$ & 0.883 & 0.252 & 0.302 & 0.076 & \\
\hline
\end{tabular}

t: Student's t test, d: Welch's d test, F: F-test. 
Table 2 Colorimetric and gas chromatographic (*) monitoring of urinary HGA in a 5-year old girl with AKU. Urine sam- ples were collected over 24 hours. At the age of 4 and 5 years, samples were collected on 3 consecutive days.

\begin{tabular}{|c|c|c|c|c|c|}
\hline $\begin{array}{l}\text { Age } \\
\text { (years) }\end{array}$ & $\begin{array}{l}\text { HGA } \\
\text { (mg/l) }\end{array}$ & $\begin{array}{l}\text { Urinary } \\
\text { creatinine } \\
\text { ( } \mu \mathrm{mol} / \mathrm{l})\end{array}$ & $\begin{array}{l}\mathrm{HGA} / \\
\text { creatinine } \\
\text { (mmol } / \mathrm{mmol})\end{array}$ & $\begin{array}{l}\text { HGA/ } \\
\text { creatinine* } \\
\text { (mmol } / \mathrm{mmol} \text { ) }\end{array}$ & Therapy \\
\hline 0.5 & 2466 & 6980 & 2.10 & & \\
\hline 2 & 2634 & 3350 & 4.69 & & $\begin{array}{l}\text { Vitamin C } \\
0.5 \mathrm{~g} / \text { day }\end{array}$ \\
\hline 3 & 3460 & 4100 & 5.02 & & \\
\hline \multirow[t]{3}{*}{4} & 3421 & 9130 & 2.23 & 2.33 & \\
\hline & 3335 & 10000 & 1.98 & 2.44 & \\
\hline & 3502 & 7690 & 2.71 & 2.33 & \\
\hline \multirow[t]{3}{*}{5} & 2090 & 5610 & 2.22 & & $\begin{array}{l}1 \mathrm{~g} / \text { day vitamin } \mathrm{C}+ \\
\text { protein restriction }\end{array}$ \\
\hline & 2100 & 7980 & 1.57 & & \\
\hline & 1830 & 5010 & 2.17 & & \\
\hline
\end{tabular}

reference range given as mean + $2 \mathrm{SD}: 2.8 \mathrm{mg} / \mathrm{mmol}$ ). Age-dependent reference ranges for the five age groups are given as mean $+\mathrm{SD}$ of $\mathrm{HGA} /$ creatinine and HGA in Table 1.

Urinary HGA values of our AKU patient are shown in Table 2. As HGA values measured by gas chromatography were similar to colorimetric results, we used only colorimetric assay for the routine monitoring of HGA in the AKU patient. Her HGA increased from 2.1 to $5.02 \mathrm{mmol} / \mathrm{mmol}$ creatinine during the first 3 years and remained between $2.71-1.57 \mathrm{mmol} / \mathrm{mmol}$ creatinine during the $4-5$ th year while she remained on high dose vitamin $C$ treatment $(0.5-1 \mathrm{~g} /$ day) for 4 years. Since the age of 4 years, her daily protein intake has been restricted $(1.1-1.3 \mathrm{~g} / \mathrm{kg})$, as this has a beneficial effect before the adolescent period (6).

\section{Discussion}

Because AKU patients' urinary HGA levels are much higher than those of healthy subjects, pathological urinary samples need predilution. Predilution and reading of absorbance after 5 min reaction time probably reduce nonspecific reactions (15). The diluted samples can be measured precisely over a wide linearity range (1-700 mg/l). Colorimetric methods, e.g., iodometric method and the reduction of silver or molybdate compound, have some disadvantages (15). Our method is based on the reduction of $\mathrm{Bi}$ ions by HGA, and the dilution of urine and calibrators was similar to those applied by Neuberger (15).

Means of urinary HGA levels determined by the present colorimetric method in children were below $12.26 \mathrm{mg} / \mathrm{l}$, and these are similar to HGA levels in normal adult plasma (2.4-12 $\mathrm{mg} / \mathrm{l})$ determined with gas chromatography-mass spectrometry (GC-MS). (17). Even though not accessible every time, GC-MS, using stable isotope dilution, is to be considered the gold standard for measuring urinary HGA (17).

At our pediatric department during the past decades
AKU in children was considered as an inborn metabolic disease with few clinical symptoms, because the consequences of HGA deposition, pigmentation in connective tissues, and arthropathy arise generally at adult age. However, the oxido-reductive effect of excess HGA on human hemoglobin and the connection between AKU and coronary artery disease have been explored recently (18). These data will modify the previous views on AKU, and HGA cannot be considered as a harmless metabolite any more. Moreover, the oxidative DNA damage induced by HGA (19) means the possibility of mutagenic effect. To reduce these consequences, we suggest to monitor HGA since childhood and emphasize the importance of individual HGA monitoring in AKU patients. Although diet restriction and vitamin $\mathrm{C}$ therapy might only delay or possibly reduce pathologic changes (6), the measurement of HGA helps with the decision about starting protein-restricted diet or other treatment and can be used to evaluate the effectiveness of the therapy.

\section{References}

1. O'Brien WM, La Du BN, Bunim JJ. Biochemical, pathologic and clinical aspects of alkaptonuria, ochronosis and chronic arthropathy. Review of world literature (1584-1962). Am J Med 1963; 34:813-38.

2. Montagutelli $X$, Laloutte $A$, Coudé $M$, Kamoun $P$, Forest $M$, Guénet JL. Aku, a mutation of the mouse homologous to human alkaptonuria, maps to chromosome 16. Genomics 1994; 19:9-11.

3. Zatkova A, de-Bernabe DB, Polakova H, Zvarik M, Ferakova $\mathrm{E}$, Bosak $\mathrm{V}$, et al. High frequency of alkaptonuria in Slovakia: evidence for the appearance of multiple mutations in HGO involving different mutational hot spots. Am J Hum Genet 2000; 67:1333-9.

4. Bosacco SJ, Fye M, Finn CA. Alkaptonuria and achronosis. Orthopedics 1991; 14:394-7.

5. Obadas AR, Karakuzu A, Selcuk Y, Erdem T, Cetiakaya R. Alkaptonuria a case report. J Dermatol 2001; 28:158-60.

6. Haas V, Carbascus W, Klerk JBC, Bakker HD, Smit GPA, Huijbers WAR, et al. The success of dietary protein restriction in 
alkaptonuria patients is age-dependent. $\mathrm{J}$ Inher Metab Dis 1998; 21:791-8.

7. Akezawa M, Takasaki M, Tomoda A. Oscillatory oxido-reductive reaction of intra-cellular hemoglobin in human erythrocyte incubated with o-aminophenol. Tohoku J Exp Med 1998; 192:301-12.

8. Yoneda Y, Akazawa M, Koizumi J, Takasaki M, Yamaguchi $\mathrm{J}$, Tomoda A. Multi- effective properties of homogentisic acid revealed in reaction with human hemoglobin and human erythrocytic hemoglobin. Int J Hematol 2000; 72:31824.

9. Lustberg TJ, Schulman JD, Seegmiller JE. Decreased binding of 14-C-homogentisic acid induced by ascorbic acid in connective tissues of rats with experimental alkaptonuria. Nature 1970; 228:770-1.

10. Mayatepek E, Kallas K, Annimos A, Müller E. Effect of ascorbic acid and low-protein diet in alkaptonuria. J Inher Metab Dis 1997; 20:Suppl 1:30.

11. Wolf JA, Barshop B, Nyhan WL, Leslie J, Seegmiller JE, Gruber $\mathrm{H}$, et al. Effect of ascorbic acid in alkaptonuria: alteration in benzoquinone acetic acid and an ontogenic effect in infancy. Ped Res 1989; 26:140-4.

12. Cabras P, Angioni A, Tuberoso C, Floris I, Reniero F, Guillou $C$, et al. Homogentisic acid: a phenolic acid as a marker of strawberry-tree honey. J Agric Food Chem 1999; 47:40647.

13. Presto-Elgstoen KB, Jellum E. Capillary electrophoresis for diagnosis of metabolic disease. Electrophoresis 1997; 18:1857-60.
14. La Du BN, Zannoni VG. The tyrosine oxidation system of liver II. Oxidation of $p$-hydroxyphenylpyruvic acid to homogentisic acid. J Biol Chem 1955; 217:777-87.

15. Neuberger A. Studies on alcaptonuria. 1. The estimation of homogentisic acid. Biochem J 1947; 41:431-8.

16. Tanaka K, Hine DG, West-Dull A, Lynn TB. Gas-chromatographic method of analysis for urinary organic acids. I. Retention indices of 155 metabolically important compounds. Clin Chem 1980; 26:1839-46.

17. Deutsch JC, Santhosh-Kumar CR. Quantitation of homogentisic acid in normal human plasma. J Chromatogr B Biomed Appl 1996; 677:147-51.

18. Vavuranakis M, Triantafillidi H, Stefanadis C, Toutouzas P. Aortic stenosis and coronary artery disease caused by alkaptonuria, a rare metabolic syndrome. Cardiology 1998; 90:302-4

19. Hiraku Y, Yamasaki M, Kawasaki S. Oxidative DNA damage induced by homogentisic acid, a tyrosine metabolite. FEBS Lett 1998; 432:13-6.

Received 16 July 2002, revised 27 November 2002, accepted 29 November 2002

Corresponding author: Anna V. Oláh, PhD, Department of Clinical Biochemistry and Molecular Pathology, University of Debrecen, Medical and Health Science Center, POB 40,

Debrecen, 4012, Hungary

Phone: + 36-52-432 283, Fax: + 36-52-417-631,

E-mail: olaha@jaguar.dote.hu 